\title{
SINTOMATOLOGIA DA MURCHA DE Ceratocystis fimbriata EM EUCALIPTO ${ }^{1}$
}

\author{
Francisco Alves Ferreira², Luiz Antônio Maffia², Robert Weingart Barreto², Nerino Luiz Demuner ${ }^{2}$ e \\ Silvana Pigatto ${ }^{2}$
}

\begin{abstract}
RESUMO - Descreveram-se o histórico da murcha de Ceratocystis fimbriata em eucalipto no Brasil e em outros países e a sintomatologia da doença, em plantações clonais com 4 meses a 5 anos de idade, em brotações de tocos, em estacas em enraizamento e em mudas clonais em viveiro, de quatro estados brasileiros. O patógeno evoluía-se da extremidade da raiz, atingindo o colo e tronco acima via parênquima medular, de onde, em diversas alturas, surgiam estrias escuras, que progrediam, via parênquima radial, matando uma porção de câmbio vascular, de floema e de feloderme. Dessa progressão sistêmica do patógeno, ascendente e radialmente, resultava uma lesão longitudinal externamente no tronco, contínua ou descontínua, marrom-avermelhada, coriácea, que passava a sulcada e, posteriormente, a cancro longitudinal, com seus calos longilíneos nas duas laterais. Por esse contexto sintomatológico, pode-se considerar essa enfermidade como um modelo de doença sistêmica em essência florestal, pelo menos na subárea da patologia florestal brasileira. Em brotações novas, em estacas em enraizamento e em mudas clonais as lesões eram longitudinais, contínuas ou descontínuas, negras a arroxeadas. A inativação de xilema em raízes, colo e em diferentes alturas do tronco, ou galho, dava-se pelo adensamento das estrias radiais escuras no lenho.
\end{abstract}

Palavras-chave: Eucalipto, Ceratocystis fimbriata, doença e sintomas.

\section{SYMPTOMATOLOGY OF CERATOCYSTIS WILT IN EUCALYPTUS}

\begin{abstract}
The symptomatology of Ceratocystis fimbriata wilt in eucalyptus was described based on observations of 4-month to 5-year-old clonal plantations, in stump sprouts, rooting cuttings, and rooted seedlings in nurseries. The disease was characterized as a model of systemic disease in woody plants, which starts in roots and progresses upward to the collar and trunk through the medullar parenchyma, where dark stripes irradiate and lead a portion of the vascular cambium, phloem and phelloderm to death. As the pathogen spread upward and radially, a longitudinal reddish-brown, continuous or non-continuous corky lesion appeared outside the trunk. Later, it turned into a furrowed, brownish, and finally longitudinal canker with callus on both sides. In infected young sprouts, cuttings, and seedlings, the lesions were longitudinal and bluish-black or purple. The xylem was inactivated by compression of the radial stripes in some woody segments.
\end{abstract}

Keywords: Eucalyptus, Ceratocystis fimbriata, disease and symptoms.

\section{INTRODUÇÃO}

O grande interesse do Brasil pelo eucalipto, essência florestal australiana, dá-se pelos seguintes aspectos:

$1^{\circ}$. O gênero Eucalyptus inclui dezenas de espécies adaptáveis às diversas regiões brasileiras.

$2^{\circ}$. Várias dessas espécies apresentam crescimento relativamente rápido e madeira de qualidade muito satisfatória para celulose, papel, carvão vegetal, postes, moirões, construção civil, móveis, chapas de fibras e de partículas etc.

$3^{\circ}$. É uma essência florestal relativamente fácil para ser trabalhada e manejada nos âmbitos silvicultural e tecnológico (ALFENAS et al., 2004; FAO, 1993; CIESLA et al., 1995).

\footnotetext{
${ }^{1}$ Recebido em 29.03.2005 e aceito para publicação em 10.11.2005.

${ }^{2}$ Departamento de Fitopatologia da Universidade Federal de Viçosa, 36570-000 Viçosa-MG.
} 
Ressalta-se ainda que, para finalidades específicas do eucalipto, por exemplo, para celulose, que representa a sua maior destinação no país e no mundo, o Brasil detém uma das maiores produtividades e uma das menores idades de rotação das plantações (ALFENAS et al., 2004; FERREIRA e MILANI, 2002).

Como outras plantas cultivadas, o eucalipto é também afetado por doenças e pragas que, se não forem estudadas e controladas logo, podem comprometer a produtividade e qualidade das plantações (FERREIRA, 1989). Várias doenças têm incidido na cultura do eucalipto após a sua introdução no Brasil. Entretanto, com os esforços imediatos de algumas subáreas florestais, como a Silvicultura, o Melhoramento, a Entomologia e a Patologia Florestais, têm-se obtido respostas satisfatórias no que se refere à etiologia e ao oferecimento de alternativas de controle, implementadas pela iniciativa privada. Foi assim, por exemplo, com o cancro do eucalipto, causado por Cryphonectria cubensis (Bruner) Hodges, e a ferrugem do eucalipto, causada por Puccinia psidii Winter (FERREIRA, 1977, 1983, 1989; ALFENAS et al., 1993; FERREIRA et al., 1978; CASTRO, 1983; HODGES et al., 1976; KRUGNER, 1983; RUIZ, 1988).

$\mathrm{Na}$ atualidade, os técnicos envolvidos com a eucaliptocultura clonal, especialmente nas terras baixas do Estado do Espírito Santo e sudeste da Bahia, têmse mantido em alerta com as ocorrências de novas doenças abióticas e bióticas, as quais vêm acarretando, em média, refugo de um genótipo (clone) a cada 510 anos. Isso faz que haja necessidade de incorporar, constantemente, novos genótipos silvicultural e tecnologicamente nobres à reserva clonal das respectivas empresas.

A partir de dezembro de 1997, tem-se constatado uma nova doença nos reflorestamentos clonais de eucalipto no sudeste da Bahia, causada por Ceratocystis fimbriata Ellis e Halsted (FERREIRA et al., 1999; FERREIRA, 2000). Essa doença vem causando sérias preocupações, uma vez que aos 18 meses de lida com a enfermidade se observou, em áreas de determinados talhões monoclonais, mortalidade de plantas superior a $40 \%$, sendo que nos primeiros meses de observação da doença as perdas não excediam a 20-25\%. No primeiro ano, a enfermidade limitava-se a plantações monoclonais de dois genótipos. Posteriormente, três outros genótipos apresentaram também a doença. Como agravante, em anos posteriores constatou-se a enfermidade em hastes de brotações em banco clonal destinadas ao enraizamento de estacas, em estacas em enraizamento dentro de casa de vegetação e em mudas já enraizadas na fase de aclimatação, no viveiro, a céu aberto. Essas últimas constatações significaram haver considerável risco de se introduzir a doença em áreas ainda sem o patógeno, via mudas propagadas vegetativamente. Hoje, essa enfermidade afeta 10 clones, em quatro estados brasileiros. Assim, o objetivo deste trabalho foi descrever o histórico e a sintomatologia dessa patologia em eucalipto.

\section{MATERIAL E MÉTODOS}

Pesquisou-se o histórico da murcha de C. fimbriata em eucalipto em outros países, utilizando-se a literatura fitopatológica disponível, para conhecer as possíveis similaridades e, ou, diferenças etiológicas e epidemiológicas entre a doença no Brasil e aquelas descritas em outros países.

Os sintomas da enfermidade foram estudados no Brasil, em material doente, envolvendo 10 clones diferentes, pertencentes a oito empresas eucaliptocultoras, em plantações nos Estados da Bahia (sudeste e Recôncavo baiano), de Minas Gerais (Vale do Jequitinhonha e região oeste), São Paulo (região central) e Mato Grosso do Sul (sul). As observações sintomatológicas deram-se em diferentes épocas anuais, em viveiro e campo e em material doente remetido ao Laboratório de Patologia Florestal da Universidade Federal de Viçosa, por empresas florestais, no período de dezembro de 1997 a maio de 2004. As idades das plantas doentes, de plantios iniciais ou de brotações pós-corte raso variaram de quatro meses a cinco anos. No estudo sintomatológico, deuse atenção especial à eventual associação da doença a ferimentos e perfurações por insetos nos troncos, uma vez que várias enfermidades causadas por Ceratocystis spp. em outras plantas lenhosas têm apresentado suas etiologias associadas às injurias mecânicas, salinoplasmolizantes e por insetos (WINGFIELD et al., 1993; SINCLAIR et al., 1987). No caso de associação de inseto, na inspeção do material enfermo, ou morto, procurou-se determinar se a associação fora a precursora da doença ou a que a sucedeu. Após esses cuidados, anotaram-se os sintomas encontrados externa e internamente nos órgãos das plantas, utilizando, quando necessário, cortes longitudinais e transversais com facão e, ou, motosserra. A descrição dos sintomas externos e internos e demais observações importantes para o entendimento da enfermidade foram feitas com 
base nos conhecimentos dos mecanismos de defesa das árvores em nível de casca e lenho (MULLICK, 1977; SHIGO, 1979; FERREIRA, 1989; BLANCHETTEeBIGGS, 1992; PEARCE, 1996), que são imprescindíveis para se entender o progresso de uma doença em órgão lenhoso (FERREIRA e MILANI, 2002). Ressalta-se que a falta desses conhecimentos nas descrições sintomatológicas das doenças causadas por C. fimbriata em eucalipto e em outras plantas lenhosas tem sido a principal razão de não se poder em utilizar alguma(s) dela(s) como modelo para o estudo dessa doença em eucalipto. Basicamente, os mesmos cuidados observados no estudo sintomatológico de plantas no campo foram também seguidos na descrição dos sintomas nas estacas em enraizamento dentro de casas de vegetação, nas mudas enraizadas na fase de aclimatação em viveiro, a céu aberto, e nas brotações em banco clonal no campo, destinadas ao enraizamento de estacas.

\section{RESULTADOS E DISCUSSÃO}

O Brasil e o Uruguai foram os únicos países das Américas onde até então se constatou a murcha de C. fimbriata em eucalipto (FERREIRA et al., 1999; BARNES, 2003). Fora das Américas, a doença foi registrada em Uganda e República do Congo (ROUX et al., 2000, 2001). No Brasil, sem que houvesse registro em literatura, em 1975 o primeiro autor constatou a doença em hastes de E. tereticornis Sm., com cerca de oito meses de idade, enviadas por empresa florestal do sudeste da Bahia. Com a extinção dessa empresa, as suas plantações foram transferidas para outra, que passou a ter a doença a partir de dezembro de 1997 , em talhões de somente um de seus clones, o qual, por cerca de nove anos, vinha sendo plantado comercialmente, sem que se percebesse a ocorrência da murcha de C. fimbriata. Na década de 1980, nessa mesma empresa, numa diagnose em estacas propagativas mortas, que não chegaram a enraizar, o primeiro autor constatou frutificações de $C$. fimbriata sem relacionálas à causa da mortalidade das estacas, que foi atribuída a fatores abióticos e, ou, associação de Cylindrocladium spp. e Rhizoctonia solani.

Fora do sudeste do Estado da Bahia, a primeira constatação da murcha de $C$. fimbriata em eucalipto deu-se em maio de 2001, no sul do Estado de Mato Grosso do Sul, quando o primeiro autor constatou a doença numa plantação monoclonal de E. grandis, envolvendo cerca de 30 árvores, com um ano e três meses de idade, próxima a uma beirada de estrada secundária. Em 2003, constatou-se a doença numa única árvore clonal de uma plantação de E. grandis, no Vale do Jequitinhonha, no Estado de Minas Gerais, e no Recôncavo baiano, em plantações monoclonais de três clones de eucalipto. Em 2004, a doença foi constatada em quatro sub-regiões do oeste de Minas Gerais, envolvendo plantações de um único clone, com pouco mais de um ano de idade, cujas mudas foram originárias de uma única safra de mudas de um viveiro. Ainda em 2004, na região central do Estado de São Paulo, em plantações de um único clone constatou-se a murcha de C. fimbriata, sendo que o clone afetado fora introduzido via mudas originárias daquele clone, que a partir 1997 passou a ter os surtos mais severos da doença no sudeste baiano. Com base em observações histopatológicas em campo, iniciadas em março de 2003, e pelas características do surgimento da enfermidade no Estado de São Paulo e dispersão da doença no oeste de Minas Gerais, passou-se a dar crédito à suspeita de que essa doença poderia ser também transmissível por meio de mudas clonais.

Em campo, a murcha de C. fimbriata em eucalipto tem-se revelado uma doença clonal-específica, que tem afetado uma minoria de clones de empresas florestais, tendo amplo germoplasma clonal. No entanto, nessa minoria suscetível geralmente há clone(s) nobre (s), dos pontos de vista silvicultural e tecnológico, e por isso são válidos os esforços para se entender melhor essa doença e obter o seu controle.

Nas primeiras investigações da enfermidade, em plantas de quatro a seis meses de idade, de plantações monoclonais de primeiro ciclo e de brotações no sudeste da Bahia, observou-se início de murchamento da copa ou de apenas um galho, que tem sido denominado "galhobandeira”. Com o passar do tempo, essa murcha progredia, afetando toda a planta e levando-a à morte. Esses sintomas se davam em plantas isoladamente, ou agrupadas em algum(ns) setor(es) do talhão, sem a caracterização de uma reboleira típica. Nos sintomas novos, o que chamava mais a atenção era a lesão longitudinal, marrom-avermelhada, coriácea, basalascendentemente na haste, contínua ou descontínua (Figura 1), a partir do colo. Paulatinamente, essa lesão se tornava mais larga, sulcada e amarronzada, transformando-se em cancro longitudinal, com seus calos laterais (Figura2). Nas primeiras diagnoses, em dezembro de 1997 o formato longitudinal dessa lesão

R. Árvore, Viçosa-MG, v.30, n.2, p.155-162, 2006 
foi tido como discrepante daquele esperado para uma lesão fúngica em tronco que, em geral, tem o padrão inicialmente circular, passando a elíptico (FERREIRA e MILANI, 2002). Sob binocular estereoscópica, notouse que, externamente no tronco, a casca da lesão longitudinal estava tomada por frutificações de Cryptosporiopsis eucalypti Sankaran \& Sutton, fungo causador da mancha foliar em eucalipto (SANKARAN et al., 1995; FERREIRA et al., 1998). Assim, preliminarmente inferiu-se que o fator causal primário da lesão não era de origem fúngica, sendo, provavelmente, de origem abiótica, em razão do seu formato (FERREIRA e MILANI, 2002), com interação fúngica. Além disso, tinha-se em mente que a quase totalidade das lesões fúngicas ou injúrias tem o seu início e progresso nos troncos, no sentido exterior-interior. Essas observações sobre o formato da lesão se repetiram em outras hastes doentes que foram requisitadas, mas a abundante associação fúngica na casca da lesão mudara para Pestalotiopsis sp., fungo oportunista que, em eucalipto, tem sido visto colonizando, pioneiramente, porções de tecidos foliares e de casca mortos por fatores abióticos, como geada (FERREIRA e MILANI, 2002). Uma vez constada essa alternância da associação fúngica na casca, desviaram-se as investigações para o lenho, fazendo cortes transversais em variadas alturas da lesão longitudinal. Observou-se que onde ela se mostrava descontínua, externamente na casca, estrias escuras surgiam da medula e progrediam no sentido radial, mas se mantinham ainda no lenho sem, no entanto, ainda atingir o câmbio vascular e a casca interna (Figura 1). Quando a secção passava em uma altura em que a lesão longitudinal era contínua na casca externa, estrias escuras surgiam também da medula, progrediam radialmente, atingindo o câmbio vascular e os tecidos da casca interna, dando origem ao externamento de lesão na casca da haste (Figura1), ou seja, esse progresso ascendente e radial da doença a partir da medula configurava o inequívoco aspecto sistêmico da doença (Figura 1). Ressalta-se que o progresso ascendente do patógeno, via parênquima medular, é favorecido pelo fato de esse tecido ser o primeiro a morrer naturalmente no lenho (informação pessoal do professor da UFV E. Monteiro, 2002).

Isolamentos de microrganismos para o meio de cultura BDA, a partir de fragmentos de tecidos do parênquima medular doente, com as estrias radiais em progressão no lenho, freqüentemente deram origem ao fungo $C$. fimbriata, que passou à condição de agente causal da lesão longitudinal e da própria nova doença do eucalipto, conforme provas de patogenicidade realizadas por Ferreira et al. (1999) e Laia et al. (2000).

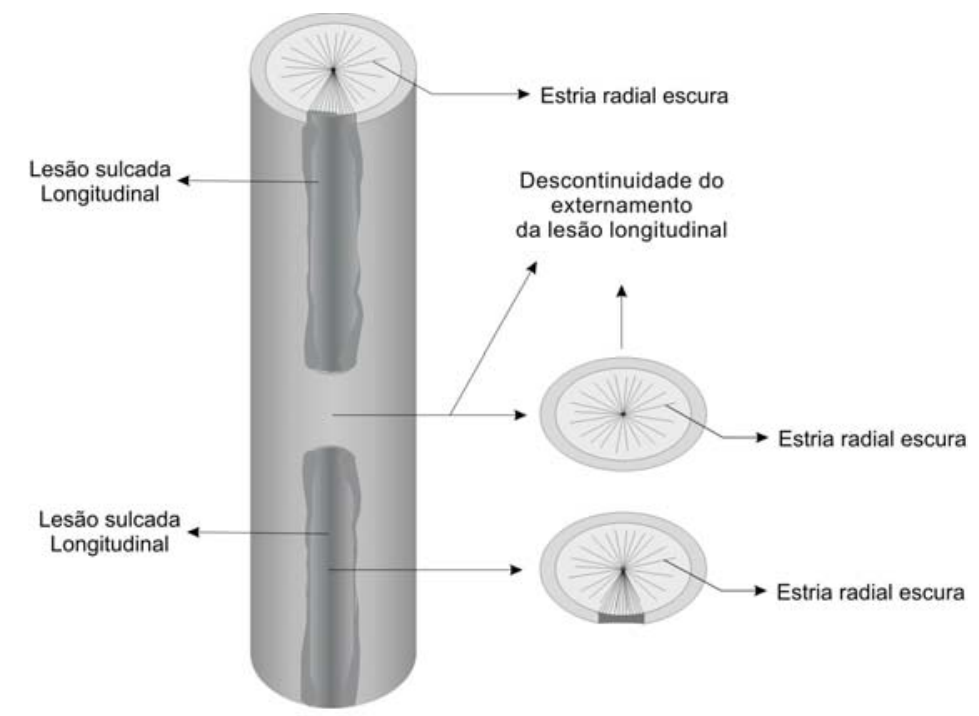

Figura 1 - Desenho esquemático do externamento de lesões longitudinais causadas por Ceratocystis fimbriata em Eucalyptus grandis e respectivas secções transversais.

Figure 1 - Schematic drawing of outwarding of longitudinal lesions caused by Ceratocystis fimbriata in Eucalyptus grandis and respective sections.

R. Árvore, Viçosa-MG, v.30, n.2, p.155-162, 2006 


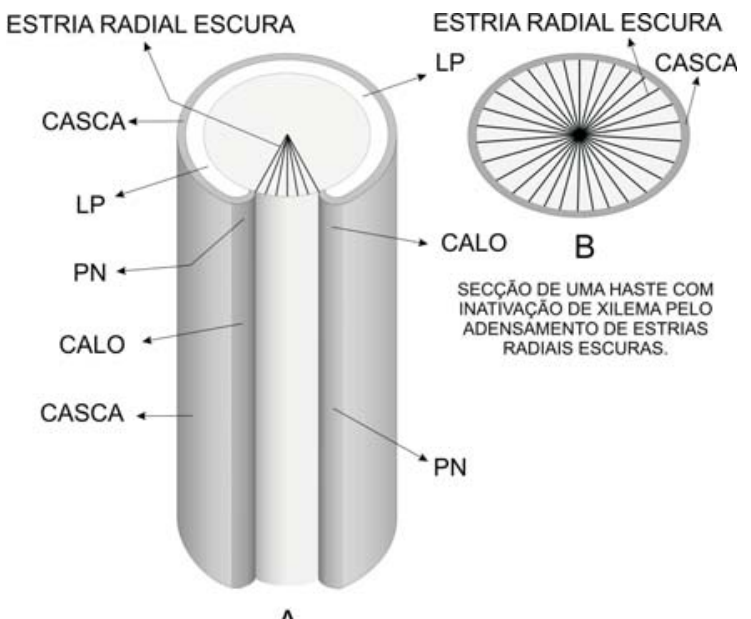

A

Figura 2 - Sintoma de cancro na doença de murcha de Ceratocystis fimbriata em eucalipto.

Figure 2 - Canker symptom of the wilt disease caused by Ceratocystis fimbriata in Eucalyptus.

O câmbio vascular sadio, à direita e à esquerda da porção cambial morta, inicia a produção de lenho pós-morte da porção cambial (= lenho posterior $=$ LP) (Figura 2A), o qual é recoberto por periderme necrofilática, sendo chamado de calo, cuja definição, em planta lenhosa, é "periderme necrofilática recobrindo LP" (FERREIRA, 1997ab; FERREIRA e MILANI, 2002). Tão logo o LP é produzido, ele é preferencialmente usado para a subida de água e sais minerais, enquanto o lenho anterior aquele existente até se ter o início de morte da porção cambial - vai sendo paulatinamente abandonado fisiologicamente (FERREIRA e MILANI, 2002). Em condições naturais, parte das árvores infectadas que não morrem é vista portando a lesão sulcada, longitudinal e amarronzada, ladeada por calos longilíneos, escuros e rugosos, de até mais de $2 \mathrm{~m}$ de comprimento (Figura 2 A). Quando o adensamento das estrias radiais escuras toma toda a circunferência interna do lenho das raízes ou do colo, ocorre a inativação de xilema e a árvore morre (Figura 2 B). Se a inativação de xilema ocorrer em uma altura elevada da haste principal, têm-se a murcha e subseqüente morte do segmento terminal, havendo, por isso, alteração do balanço hormonal, resultando na emissão de brotações adventícias em setores medianos e basais do tronco (FERREIRA, 1989; FERREIRA e MILANI, 2002). Quando se tem morte do setor apical em consequiência de estresse hídrico em alguma árvore já infectada por C. fimbriata, o avanço do patógeno, ascendentemente, é muito rápido, observando-se gradativo aumento de adensamento das estrias radiais escuras nas secções, no sentido base-ápice.

Inspeções de campo para relacionar os sintomas observados na parte aérea das plantas propensas a infecções radiculares foram positivas, isto é, em várias plantas investigadas, das extremidades de raízes mortas até as proximidades do colo, observou-se o sintoma marcador do ataque de $C$. fimbriata no lenho-as estrias radiais no lenho. Em algumas raízes mais grossas, observaram-se morte da extremidade apical e progresso de lesão sulcada, análoga àquela em tronco, que progredia até o colo e, daí, tronco acima. Fragmentos de seus lenhos propiciaram colônias de $C$. fimbriata. Nas plantas ainda vivas, com sintomas da doença na parte aérea, somente algumas das raízes apresentaram-se mortas. Também, a constatação do referido sintoma de "galhobandeira" correspondeu à presença de raiz(es) infectada(s), xilematicamente vinculada(s) àquele lado do tronco com o galho visto doente. Até então, não se observaram injúrias mecânicas ou a atuação de insetos associados à morte das raízes.

Um aspecto importante do surgimento da murcha de C. fimbriata no Brasil relacionou-se aos anos de 1997 e 1998, que apresentaram déficit hídrico anormal em relação à pluviometria média da região do sudeste da Bahia. Também, o surgimento da doença, a partir de 2001, em plantações monoclonais nos Estados de Mato Grosso do Sul, da Bahia, de Minas Gerais e de São Paulo foi relacionado à última época de estiagem.

Em grande número de plantas clonais de eucalipto afetadas pela murcha de $C$. fimbriata e inspecionadas em todo o Brasil, somente duas apresentaram perfurações de inseto (da família Platybodidae) na lesão longitudinal, sulcada, amarronzada, basal-ascendente no tronco. Como não se constataram perfurações de insetos nas lesões novas, longitudinais, das plantas vizinhas, a associação de insetos somente em lesões mais velhas foi interpretada como secundária ou não precursora da doença. Provavelmente o(s) inseto(s) foi(ram) atraído(s) para a lesão em decorrência de exalamento de alguma substância química, via lenticelas ou trincamento de casca e, ou, de lenho, resultante do processo de doença no xilema, causado por $C$. fimbriata (HANSSEN, 1993). Todavia, esses insetos, ao saírem das galerias do lenho infectado, podem transmitir

R. Árvore, Viçosa-MG, v.30, n.2, p.155-162, 2006 
endoconídios e clamidósporos do patógeno para outras plantas lenhosas com xilema alterado por fator abiótico ou biótico, como acontece com outras doenças por $C$. fimbriata em outras culturas (SINCLAIR et al., 1987; WINGFIELDetal., 1993; BAKEReHARRINGTON, 2004).

A murcha de $C$. fimbriata foi também encontrada em brotações de tocos de banco clonal, destinadas ao enraizamento de estacas no sudeste da Bahia, no mesmo clone $\mathrm{C} 1$ afetado em plantações comerciais. As lesões observadas foram longitudinais, escuras, contínuas nos setores basais e descontínuas, especialmente no setor mediano das hastes. Desse material, quatro hastes foram rigorosamente selecionadas e trazidas para o Laboratório de Patologia Florestal do Departamento de Fitopatologia da Universidade Federal de Viçosa, apresentando sintomas e sinais da doença nos primeiros 15 a $20 \mathrm{~cm}$ basais. De cada haste se procedeu a isolamentos do patógeno para o meio de cultura BDA, a partir da medula, nas alturas de 25, 35,45 e $55 \mathrm{~cm}$. Do quarto ao oitavo dia, anotou-se a detecção de $C$. fimbriata. Afora as constatações do patógeno nos primeiros 15 a $20 \mathrm{~cm}$ basais de todas as quatro hastes, somente na primeira e terceira hastes se constatou o patogeno, via isolamento em BDA, a partir do setor intermediário, cuja casca tinha tonalidade avermelhada, natural, indicando que, se essas duas hastes fossem aproveitadas para o enraizamento, seriam elas veiculadoras do patógeno sistemicamente. Mesmo com a recomendação de não se coletar material propagativo em cepa onde se observou infecção de alguma(s) brotação(ões), a constatação do resultado do isolamento fúngico anterior conduziu à suspeita de haver uma chance considerável de se levar material propagativo infectado sistemicamente com C. fimbriata para o sistema de enraizamento. Além disso, o fato de algumas empresas fazerem a coleta de material propagativo de madrugada aumentava consideravelmente o risco de se levarem hastes de brotações infectadas sistemicamente. Daí, provavelmente, resultaram as constatações de mortalidade de estacas pela doença dentro de casas de vegetação e em mudas enraizadas no viveiro na fase de aclimatação, a céu aberto (FERREIRA, 2004). Todo esse contexto tem sido levado à consideração de várias eucaliptocultoras clonais, advertindo-as de que, com a tecnologia de produção de mudas por macroestaquia a partir de brotações de bancos clonais ou de plantações pós-corte raso, corre-se grande risco de disseminar o patógeno via muda clonal com infecção sistêmica. Entretanto, utilizando-se viveiro suspenso em regime de higiene (FERREIRA, 1997ab; FERREIRA e MILANI, 2002) e a técnica de enraizamento por microestaquia, ou miniestaquia com cepas sabidamente não veiculadoras do patógeno, espera-se que o risco de disseminação da doença via muda clonal deva diminuir drasticamente.

A murcha de $C$. fimbriata foi também constatada em viveiro, no sudeste da Bahia, associada ao mesmo clone que apresentou os primeiros surtos da doença em plantações. Dentro de casas de vegetação para enraizamento, a enfermidade foi detectada em estacas recém-mortas sem, ainda, terem emitido raízes e, minoritariamente, em estacas enraizadas. Em mudas enraizadas em fase de aclimatação, a céu aberto, a doença foi observada somente em duas mudas. Nesses materiais, as lesões foram longitudinais, escuras, com um tom azulado a arroxeado, contínuas ou descontínuas e geralmente situadas em um dos lados da haste.

Dentre as doenças sistêmicas causadas por espécies de Ceratocystis e outros gêneros de patógenos, apresentados por Sinclair et al. (1997), a enfermidade "sapstreak disease" do "sugar maple" (Acer saccharum Marsh) - causada por Ceratocystis virescens, que ocorre nos Estados de Winsconsin, Vermont, North Carolina e Tennessee, EUA - foi a única que teve a interpretação sintomatológica e a dinâmica de atuação do patógeno análogas ao da murcha de C.fimbriata em eucalipto no Brasil. Alguns aspectos em que a doença americana difere desta do eucalipto são: inicialmente, a enfermidade está associada a um declínio geral das árvores, cuja morte se dá após 2-4 anos do surgimento dos primeiros sintomas; a inativação de xilema dá-se nas porções basais dos troncos ou das raízes mais grossas, por lesão encharcada. No entanto, o ponto mais contundente da similaridade da "sapstreak disease" com a murcha de $C$. fimbriata em eucalipto no Brasil, detectada na descrição de Sinclair et al. (1997), deu-se quando esses autores afirmaram que "a morte cambial e a formação de cancro alongado ocorrem quando a lesão se aproxima do câmbio vascular". Em outro ponto, os autores mencionaram o desenvolvimento de estrias escuras ou avermelhadas no sentido dos raios, produzindo o sintoma típico e radiado da enfermidade nas secções transversais, o qual, em parte, corresponde ao sintoma marcador da murcha de $C$. fimbriata em eucalipto no Brasil. Infelizmente, pela escassez de detalhes sintomatológicos e pela falta de inclusão dos 
conhecimentos relacionados às defesas das árvores, visualmente perceptíveis, em nível de casca e lenho, não há como se estabelecer uma comparação satisfatória entre as doenças assinaladas em Uganda, República do Congo e Uruguai com a murcha de C. fimbriata em eucalipto no Brasil, cujos hospedeiros são da mesma espécie: E. grandis. No Uruguai, teve-se uma observação importante, relacionando-se a enfermidade às injúrias mecânicas provocadas pelas desramas artificiais (BARNES et al., 2003), o que até então não se observou no Brasil.

\section{CONCLUSÕES}

A murcha de $C$. fimbriata em eucalipto ocorre, até então, em quatro países, e é economicamente importante em conseqüência da mortalidade que causa em plantações e no sistema de produção de mudas clonais.

O detalhamento sintomatológico estudado e apresentado para essa doença no Brasil a deixou como modelo de enfermidade sistêmica em planta lenhosa, pelo menos para a subárea patologia florestal brasileira, em razão do progresso do patógeno, ascendentemente, via parênquima medular e, radialmente, a partir da medula, via parênquima radial, lesionando, seqüencialmente, uma porção ou a totalidade do câmbio, da feloderme, tendo-se externamento de lesão longitudinal, que se transforma em cancro de mesmo formato.

\section{REFERÊNCIAS BIBLIOGRÁFICAS}

\author{
AlfenAS, A. C. et al. Clonagem e \\ doenças do eucalipto. Viçosa, MG: \\ Editora UFV, 2004. 442 p.
}

ALFENAS, A. C. et al. Eficiência de triadimenol,oxicarboxim e diniconazole para o controle da ferrugem (Puccinia psidii) em brotações de Eucalyptus cloeziana, em condições de campo. Revista Árvore, v. 17, p. 247-263, 1993.

BARNES, I. et al. Ceratocystis fimbriata infecting Eucalyptus grandis in Uruguai. Australian Plant Pathology, v. 32, p.361-366, 2003.

BAKER, C. J.; HARRINGTON, T.C. Ceratocystis fimbriata. Kew, Surrey: CABI Publishing, 2004. 14 p.

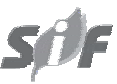

BLANCHETte, R. A.; BIGGS, A. R. Defense mechanisms of wood plants against fungi. Berlim: Spring-Verlerlag, 1992. $458 \mathrm{p}$.

CAStro, H. A. Padronização de metodologia de inoculação e avaliação da resistência de Eucalyptus spp. à ferrugem causada por Puccinia psidii Winter. 1983. 116f. Tese (Doutorado em Fitopatologia) - Escola Superior de Agricultura Luiz de Queiroz, Piracicaba, 1983.

CIESLA, W. M.; DIEKMANN, M.; PUTTER, C. A. J. Eucalyptus spp. -FAO/IPGRI Technical guidelines for the safe movement of germoplasm. Rome: FAO/ IPGRI, 1995. 67 p. (FAO/IPGRI, 17)

FAO. Forest resources assessment 1990tropical countries. Rome: 993. (Forestry Papers, 112).

FERREIRA, F. A. Etiologia da murcha de Ceratocystis fimbriata em eucalipto no Brasil. 2004. 68f. Tese (Doutorado em Fitopatologia) - Universidade Federal de Viçosa, Viçosa, 2004.

FERREIRA, F. A Constatação rápida de Ceratocystis fimbriata na doença murcha de Ceratocystis em eucalipto, por meio de cortes histopatológicos à mão livre. Fitopatologia Brasileira, v.25. p. 372, 2000. Suplemento.

FERREIRA, F. A.; MILANI, D. Diagnose visual e controle das doenças abióticas e bióticas do eucalipto no Brasil. (Visual diagnosis and control of abiotic and biotic eucalyptus diseases in Brasil). Mogi-Guaçu: International Paper, 2002. 104 p.

FERREIRA, F. A. et al. Mancha de Cryptosporiopsis euclypti no Brasil. Fitopatologia Brasileira, v.23, n.3, p. 414, 1998.

FERREIRA, F. A. et al. Murcha-de-Ceratocystis em eucalpto no Brasil. Fitopatologia Brasileira, v.24, p.284, 1999. Suplemento.

FERREIRA, F. A. Enfermidades do eucalipto no Brasil. EPAMIG, Belo Horizonte. Informe

Agropecuário, v. 18, n. 186, p. 5-19, 31-50, 1997 a.

R. Árvore, Viçosa-MG, v.30, n.2, p.155-162, 2006 
FERREIRA, F. A. Eucalipto (Eucalyptus spp.). Controle de doenças. In: RIBEIRO DO VALE; ZAMBOLIM. (Eds.). Controle de doenças de plantas, Viçosa, MG: UFV, 1997b. p. 289-333.

FERREIRA, F. A. Patologia florestalprincipais doenças florestais no Brasil. Viçosa, MG: SIF, UFV, 1989. 570 p.

FERREIRA, F. A. A ferrugem do eucalipto. Revista Árvore, v. 7, n. 2, p. 92-109, 1983.

FERREIRA, F. A. Resistência de Eucalyptus spp. ao cancro causado por Diaporthe cubensis Bruner. 1977. 75f. Dissertação (Mestrado em Microbiologia Agrícola) Universidade Federal de Viçosa, Viçosa, 1977.

FERREIRA, F. A. et al. Avaliação da resistência de Eucalyptus spp. ao cancro causado por Diaporthe cubensis Bruner. Fitopatologia Brasileira, v. 3, n. 1, p. 81-85, 1978.

HANSSEN, H. P. Volatile metabolites produced by species of Ophiostoma and Ceratocystis. In: WINGFIELD, M. J.; SEIFER, K.; WEBBER, J. F. Ceratocystis and Ophiostoma. Taxonomy, ecology and patogenicity. St. Paul: APS Press, 1993. p. 117-125.

HODGES, C. S. et al. O cancro do eucalipto no Brasil causado por Diaporthe cubensis Bruner. Fitopatologia Brasileira, v. 1, n. 3, p.129-169, 1976.

KRUGNER, T.L. Variação na resistência do hospedeiro e no grau de patogenicidade do patógeno no sistema Eucalyptus grandis Hill ex Maiden - Cryphonectria cubensis (Bruner) Hodges. Fitopatologia Brasileira, v.8, p.47-64, 1983.

LAIA, M. L.; ALFENAS, A. C.; HARRINGTON, T. C. Isolation, detection in soil and inoculation of Ceratocystis fimbriata, causal agentof wilting, dieback and canker in eucalyptus. Fitopatologia Brasileira, v.25, p. 384-385, 2000.

R. Árvore, Viçosa-MG, v.30, n.2, p.155-162, 2006
MULLICK, D. B. The non-specific nature of defense in bark and wood during wound, insect and pathogen attack. In: LOWES, F. A.; RUNECKLES, V.C. Recent Advances in Phytochemistry. Nova York: Plemur Press, 1977. v.11, p. 395-441.

PEARCE, R. B. Antimicrobial defences in the wood of living trees. New Phytology, v.132, p.203-233,1996.

ROUX, J. et al. Diseases in plantation Eucalyptus in Uganda. South African Journal of Science, v. 97, p. 16-18, 2001.

ROUX, J. et al. A serious new wilt disease of eucalyptus caused by Ceratocystis fimbriata in Central África. Forest Pathology, v. 30, p.175-184, 2000.

RUIZ, R. Epidemiologia e controle químico da ferrugem (Puccinia psidii Winter) do eucalipto. 1988. $108 \mathrm{f}$. Dissertação (Mestrado em Fitopatologia) Universidade Federal de Viçosa, Viçosa, 1988.

SANKARAN, K. V. SUTTON, B. C.;

BALASUNDARAN, M. Cryptosporiopsis eucalypti sp. Nov., causing leaf spot of eucalypt in Australia, Índia, and U.S.A. Mycological Research, v. 99, n. 7, p. 827-830, 1995.

SHIGO, A. L. Tree decay -an expanded concept. Washington: USDA, Forest Service, 1979. 72 p. (Bulletin, 69)

SINCLAIR, W. A.; LYON, H. H.; JOHNSON, W. T. Diseases of trees and shrubs. Ithaca: Cornell University Press, 1987. 74 p. .

WINGFIELD, M. J. Ceratocystis and Ophiostoma, taxonomy, ecology, and pathogenicity. St. Paul: APS Press, 1993. 293 p. 